\title{
ANÁLISE COMPARATIVA DE MÉTODOS DE PURIFICAÇÃO DE ÉSTERES ETÍLICOS DA BLENDA DE SEBO BOVINO E ÓLEO DE FRITURA
}

\author{
J. V. BERNI ${ }^{1}$, N. DOLFINI ${ }^{1}$, J. F. MEDEIROS ${ }^{1}$, F. N. ALMEIDA ${ }^{1}$, N. C. PEREIRA ${ }^{1}$ \\ ${ }^{1}$ Universidade Estadual de Maringá, Departamento de Engenharia Química \\ *e-mail: jessica.v.b@ hotmail.com
}

\begin{abstract}
RESUMO
O biodiesel é uma fonte limpa, renovável e alternativa, em substituição aos combustíveis fósseis. Este produto pode ser obtido a partir da reação de transesterificação, utilizando uma matéria graxa e um álcool de cadeia curta como reagentes. A matéria graxa geralmente é derivada de oleaginosas ou, para reaproveitamento de produtos outrora considerados resíduos, utiliza-se também óleo de fritura usado e sebo bovino. As matérias-primas foram caracterizadas e o sebo bovino é constituído principalmente por ácidos graxos saturados e com alto teor de acidez $(24,85$ $\pm 0,30$ ), enquanto que no óleo de fritura tem-se maior quantidade de ácidos graxos insaturados, com acidez menor $(2,08 \pm 0,5)$, sendo assim foi produzida e utilizada a blenda destes materiais. A reação foi realizada utilizando o etanol e o ácido sulfúrico como catalisador, à $78^{\circ} \mathrm{C}$ e $350 \mathrm{rpm}$ em duplicata e com a razão molar de 1:36:0,46 (Blenda:EtOH: $\mathrm{H}_{2} \mathrm{SO}_{4}$ ). $\mathrm{O}$ produto foi purificado de três formas alternativas: em evaporador rotativo seguido de lavagem com água destilada a $90^{\circ} \mathrm{C}$; por centrifugação com água alcalina $(0,5 \% \mathrm{v} / \mathrm{v}$ de $\mathrm{NaOH}$ e $10 \%$ v/v de água destilada); por lavagem com água destilada a $80^{\circ} \mathrm{C}$ e centrifugação com sulfato de sódio anidro $\left(0,5 \%\right.$ v/v de $\mathrm{Na}_{2} \mathrm{SO}_{4}$ e $10 \%$ v/v de água destilada). O segundo método de purificação foi o mais eficaz, observando-se grande melhora no teor de glicerol livre e acidez do biodiesel, 0,5 mg $\mathrm{KOH} / \mathrm{g}$ óleo e $0,01 \%$ respectivamente, enquadrando-se dentro das exigências da ANP.
\end{abstract}

\section{INTRODUÇÃO}

Com a evolução tecnológica, foram criados inúmeros produtos, que requerem grande quantidade de energia em sua fabricação. Entretanto grande parte dessa energia é não-renovável e derivada de combustíveis fósseis, emitindo poluentes na natureza e causando grandes problemas ambientais (ROSENHAIN, 2009.).

Para colaborar com a sustentabilidade mundial, não basta só inovar nos processos de produção de combustíveis de fontes alternativas limpas e renováveis, mas sim ter a conscientização em buscar nessas fontes as que emitem menos gases poluentes na atmosfera, como a biomassa, biodiesel, etanol, energia maremotriz, solar, eólica, célula de hidrogênio, entre outras (BASHA, et al, 2009; ROSENHAIN, 2009.).

$\mathrm{O}$ leque de matérias-primas para a produção de biodiesel se abre para o uso de óleos de fritura usados, óleos não comestíveis e gordura animal, considerados resíduos. Essas matérias-primas em um processo de catálise ácida deve ajudar o biodiesel a se tornar competitivo em preço com o diesel de petróleo (ZHANG, et al., 2003; ZHENG, et al., 2006). 
O modo mais comum para produzir biodiesel é por transesterificação, podendo ser catalisada por ácido, base ou por enzimas. A transesterificação se refere a uma reação química envolvendo um catalisador, óleo e um álcool para produzir ésteres alquílicos de ácidos graxos e glicerol. O álcool de cadeia curta utilizado pode ser o metanol, etanol, propanol ou butanol. Os dois primeiros são os mais comumente empregados, especialmente o etanol por ser gerado a partir de biomassa (CUNHA, 2008; ZHANG, et al., 2003).

Após a reação, a massa reacional final é constituída de duas fases, que podem ser separadas por decantação ou centrifugação. A fase mais pesada é composta de glicerina bruta, impregnada dos excessos utilizados de álcool, de água, e de impurezas inerentes à matéria prima. A fase menos densa é constituída de uma mistura de ésteres metílicos ou etílicos, dependendo do álcool utilizado, também impregnado de excessos reacionais de álcool e de impurezas. Por essa razão é feita a purificação do biodiesel, com o objetivo de remover os excessos de glicerol, álcool e impurezas e também neutralizar o catalisador utilizado (DIB, 2010; PARENTE, 2003).

Portanto, o presente trabalho foi realizado para avaliar cuidadosamente 0 potencial de produção de biodiesel de blenda de sebo bovino e óleo residual. O principal objetivo foi comparar os diferentes métodos de purificação dos ésteres etílicos.

\section{MATERIAIS E MÉTODOS}

Nos experimentos para a caracterização da matéria-prima e para a obtenção de ésteres etílicos foi utilizado o óleo de fritura doado pelo restaurante universitário da Universidade Estadual de Maringá e sebo bovino doado pela Graxaria Osso Líder, localizado em Nova Esperança, Paraná. $\mathrm{O}$ etanol anidro foi fornecido pela Cocafé (Astorga, Paraná).
As características físico-químicas foram determinadas conforme a metodologia oficial AOCS (American Oil Chemist's Society). O catalisador utilizado foi o ácido sulfúrico obtido pelo FMAIA.

\subsection{Caracterização da matéria-prima}

As matérias-primas foram submetidas a um tratamento, contudo Leung, et al. (2006) afirma que é importante monitorar a qualidade das matérias-primas.

O óleo de fritura foi filtrado em filtro de pano e seco em bomba à vácuo acoplado a um kitassato e chapa aquecedora. $\mathrm{O}$ sebo bovino foi aquecido $(100 \mathrm{~mL})$ e diluído com $30 \mathrm{~mL}$ de éter de petróleo, esse solvente foi destilado em evaporador rotativo a $80^{\circ} \mathrm{C}$, sob vácuo ($700 \mathrm{mmHg}$ ) conforme metodologia utilizada por Oliveira (2013).

A determinação do índice de acidez foi realizada conforme o método oficial da AOAC - 940-28.

$O$ índice de saponificação foi determinado de acordo com a norma AOCS Cd 3-52.

O teor de umidade foi determinado utilizando-se um equipamento Karl Fischer, da marca Analyser, modelo Umidade controle KF-1000, pelo método ASTM D - 4377.

Para a determinação da massa específica foi utilizado um densímetro, marca Anton Paar, modelo DMA 5000.

A análise de perfil de ácidos graxos foi realizada através do método apresentado pela metodologia do Instituto Adolfo Lutz (2008), utilizando um cromatógrafo da marca Thermo Scientific, modelo Trage GC Ultra, com uma coluna da marca SGE Analytical Science, modelo BPX 70.

\subsection{Obtenção dos ésteres etílicos}

Os experimentos foram realizados em escala laboratorial para a obtenção dos ésteres etílicos a partir da blenda de óleo de fritura e sebo bovino. Na reação de transesterificação, o álcool utilizado na reação foi o etanol anidro 
por possuir a vantagem de não ser tóxico e de ser biodegradável; como catalisador foi utilizado o ácido sulfúrico.

Para o preparo da blenda foi utilizado à metodologia descrita por Oliveira (2013), com uma razão de 22:3 (óleo:sebo).

Segundo a metodologia utilizada por Abreu (2012) e Oliveira (2013) a reação de transesterificação foi realizada em um balão de 3 bocas de $2000 \mathrm{~mL}$ equipado com um agitador, um condensador de refluxo e um termômetro. $\mathrm{O}$ balão foi imerso em banho de água com temperatura constante. As reações foram realizadas a $78^{\circ} \mathrm{C}$ e $350 \mathrm{rpm}$ em duplicata, com uma razão molar de 1:36:0,46 (Blenda:EtOH: $\mathrm{H}_{2} \mathrm{SO}_{4}$ ), a reação foi acompanhada por 8 horas.

De acordo com a metodologia utilizada por Abreu (2012), após o término da reação de transesterificação, a mistura reacional foi submetida a um evaporador rotativo marca Fisatom, modelo 803, ligado a uma bomba hidro vácuo sob vácuo de $600 \mathrm{mmHg}$, e temperatura do banho a $60^{\circ} \mathrm{C}$ para a recuperação do álcool excedente. $\mathrm{O}$ produto ao ser retirado do evaporador rotativo a vácuo foi mantido em repouso em um funil de decantação de fases, onde foram separadas ambas as fases formadas, glicerina e ésteres, para que fosse realizada a lavagem com água destilada a $90^{\circ} \mathrm{C}$. Terminada a lavagem, o produto foi submetido ao processo de secagem em estufa a $105^{\circ} \mathrm{C}$ por 3 horas, onde foram removidas possíveis gotículas de água que tenham permanecido em contado com o produto.

No trabalho realizado por Medeiros (2013), após a decantação e separação do glicerol, o autor direcionou a fase superior para a etapa de purificação dos ésteres etílicos, que realizou centrifugação com adição de água acidificada a 0,5 (v/v) de $\mathrm{HCl}$. A partir dessa metodologia, foram realizadas adaptações, sendo que após a reação de transesterificação o biodiesel foi submetido a um evaporador rotativo a vácuo para a retirada do etanol seguido da centrifugação com $2000 \mathrm{rpm}$ por 5 minutos com adição de água basificada a $0,5 \%(\mathrm{v} / \mathrm{v})$ de $\mathrm{NaOH}$ e $10 \%$ (v/v) de água destilada.

Colonelli e Silva (2014), no estudo de produção de biodiesel a partir de óleo de macaúba utilizando como catalisadores a argila KSF e a resina Amberlyst ${ }^{\circledR} 15$ avaliaram a remoção do catalisador da reação de esterificação por meio de centrifugação (3000 rpm por 15 minutos). Na sequência, os ésteres foram purificados por meio de lavagens com água a $80{ }^{\circ} \mathrm{C}$ e centrifugação com sulfato de sódio anidro. Neste trabalho foi realizado um planejamento experimental fatorial $2^{3}$ com triplicata no ponto central, variando temperatura, razão molar (AGL:etanol) e percentual de catalisador, sendo que os melhores resultados ( $90 \%$ de conversão da reação) foram obtidos para a adição de $20 \%$ de catalisador ao meio reacional (em relação a massa de AGL) e temperatura de $80^{\circ} \mathrm{C}$ e razão molar (AGL:etanol) de 1:4.

Para as análises dos ésteres, foi utilizado um cromatógrafo da marca Varian, modelo CP - 3800, com detector de ionização de chama (DIC), contendo uma coluna capilar específica para separação de ésteres (BP X70 - SGE) de $30 \mathrm{~m}$ x 0,25 mm. Hélio foi utilizado como gás de arraste, numa razão split de 1:10. A análise foi realizada com programação de temperatura da coluna, iniciada a $110^{\circ} \mathrm{C}$, com aquecimento até $160^{\circ} \mathrm{C}$ a uma taxa de $8^{\circ} \mathrm{C} / \mathrm{min}$ e $230^{\circ} \mathrm{C}$ a $3,5^{\circ} \mathrm{C} / \mathrm{min}$. A temperatura do detector foi mantida em $220^{\circ} \mathrm{C}$ e a do injetor em $260^{\circ} \mathrm{C}$.

Os componentes da amostra analisada foram identificados por meio da comparação dos tempos de retenção na coluna com os tempos de retenção de uma amostra padrão. Foi utilizado um FAME Mix (Fatty Acid Methyl Ester). O padrão interno (PI) utilizado foi o éster metílico 23:0 Tricosanoato de metila (Sigma-Aldrich). Este éster foi escolhido como PI por não ter sido 
identificado como componente da amostra de ésteres produzidos.

\section{RESULTADOS E DISCUSSÃO}

As características físico-químicas das matérias-primas foram determinadas de acordo com a metodologia de caracterização. As características das matérias-primas estão apresentadas na Tabela 1 .

Tabela 1 - Características físico-químicas das matérias-primas.

\begin{tabular}{l|c|c}
\hline \multicolumn{1}{c|}{ Características } & $\begin{array}{c}\text { Óleo de } \\
\text { Fritura }\end{array}$ & $\begin{array}{c}\text { Sebo } \\
\text { Bovino }\end{array}$ \\
\hline Umidade $(\%)$ & $\begin{array}{c}0,229 \pm \\
0,03\end{array}$ & $\begin{array}{c}0,215 \pm \\
0,03\end{array}$ \\
\hline $\begin{array}{l}\text { Índice de acidez } \\
\text { (mg KOH/g óleo) }\end{array}$ & $2,08 \pm 0,5$ & $\begin{array}{c}24,85 \pm \\
0,30\end{array}$ \\
\hline $\begin{array}{l}\text { Índice de } \\
\text { saponificação }(\mathrm{mg}\end{array}$ & $\begin{array}{c}232,6 \pm \\
1,7\end{array}$ & $\begin{array}{c}224,84 \pm \\
14,4\end{array}$ \\
KOH/g óleo) & 0,918 & 0,896 \\
\hline $\begin{array}{l}\text { Densidade } 20^{\circ} \mathrm{C} \\
(\mathrm{g} / \mathrm{mL})\end{array}$ & \multicolumn{2}{|l}{} \\
\hline
\end{tabular}

Leung (2006) ressalta que o óleo de fritura tem uma acidez relativamente alta comparada com óleo puro, devido à presença de impurezas. O índice de acidez encontrado está de acordo com Leung, 2006 (2,1 $\mathrm{mgKOH} / \mathrm{g}$ de óleo) e acima dos resultados de Oliveira (2013) e Uzun, et al. (2012). O sebo bovino teve uma acidez baixa comparada a Magalhães (2010), (53 mg KOH/g óleo).

$O$ índice de saponificação das matérias-primas ficou de acordo com Oliveira (2013) e este resultado é um indicativo do comprimento da cadeia do ácido graxo.

$\mathrm{O}$ teor de umidade das matériasprimas é outro parâmetro importante, pois na presença de água os ésteres podem hidrolisar a ácidos graxos de cadeia longa, causando um aumento na acidez do biodiesel (KNOTHE et al., 2006).
A composição em ácidos graxos presentes nas matérias-primas está presentes na Tabela 2 .

Tabela 2 - Ácidos graxos presentes nas matérias primas.

\begin{tabular}{l|c|c}
\hline \multicolumn{1}{c|}{ Ácido Graxo } & $\begin{array}{c}\text { Óleo de } \\
\text { Fritura }\end{array}$ & $\begin{array}{c}\text { Sebo } \\
\text { Bovino }\end{array}$ \\
\hline Ácido Mirístico (C14:0) & - & $4,1 \%$ \\
\hline Ácido Palmítico (C16:0) & $14,8 \%$ & $19,6 \%$ \\
\hline Ácido Palmítico (C16:0) & $14,8 \%$ & $19,6 \%$ \\
\hline Ácido Esteárico (C18:0) & $14,1 \%$ & $25,6 \%$ \\
\hline Ácido Oleico (C18:1n9c) & $22,2 \%$ & $51,4 \%$ \\
\hline $\begin{array}{l}\text { Ácido Linoleico } \\
\text { (C18:2n6c) }\end{array}$ & $42,7 \%$ & $3,8 \%$ \\
\hline $\begin{array}{l}\text { Ácido Linolênico } \\
\text { (C18:3n3) }\end{array}$ & $8,7 \%$ & - \\
\hline
\end{tabular}

Podemos observar que no óleo de fritura há maior quantidade de ácidos graxos insaturados (oleico e linoleico), proporção que também é encontrada por Oliveira (2013) (22,4\% de C18: 1 n9c e $51,9 \%$ de $\mathrm{C} 18: 2 \mathrm{n} 6 \mathrm{c})$ e por Georgogianni et al. (2009), (24,5\% de C18: $1 n 9$ c e $53 \%$ de C18:2n6c). No entanto, quanto maior a razão entre os ácidos graxos insaturados e saturados, menor o ponto de liquefação, aumentando assim a fluidez e proporcionando melhores condições de desempenho no motor a baixas temperaturas (LEE et al. 2011; KNOTHE 2005).

Os ácidos graxos presentes no sebo bovino foram os mesmos analisados por Oliveira (2013). Além disso, Holanda (2004) cita que o ácido esteárico está presente em grande proporção no sebo bovino.

Zuniga et al. (2011) explica que o ponto de névoa e de fluidez de um biodiesel proveniente de gordura animal é maior que o de gordura vegetal, devido ao seu alto teor de ácidos graxos saturados, como o ácido esteárico (C18:0) e palmítico (C16:0).

Devido a estas diferenças nas características das matérias-primas, foi utilizada a blenda para a reação, desta forma, uma matéria-prima supre a necessidade da 
outra, a fim de atender as especificações exigidas pela ANP para o ser classificado biodiesel.

O biodiesel não tratado contém várias impurezas como excessos de glicerol, álcool e demais elementos (água, sedimentos e odores). A presença de glicerídeos e sabão em biodiesel, por exemplo, leva à formação de resíduos de alto teor de carbono, que pode obstruir ou bloquear o injetor do motor, enquanto que a presença de glicerol pode aumentar as emissões de aldeído e acroleína (propenal), por esses motivos é necessária a etapa de purificação (BERRIOS e SKELTON, 2008).

As características físico-químicas do biodiesel produzido a partir da blenda de óleo de fritura e sebo bovino estão representadas na Tabela 3.

Tabela 3 - Caracterização do biodiesel em relação às normas da ANP.

\begin{tabular}{|c|c|c|c|}
\hline $\begin{array}{c}\text { Caracterís- } \\
\text { ticas } \\
\text { /ANP }\end{array}$ & $\begin{array}{c}\text { Biodiesel } \\
\text { lavado } \\
\text { com água } \\
\text { destilada }\end{array}$ & $\begin{array}{l}\text { Biodiesel } \\
\text { centrifu- } \\
\text { gado } \\
\text { com } \\
\text { água } \\
\text { alcalina }\end{array}$ & $\begin{array}{c}\text { Biodiesel } \\
\text { centrifu- } \\
\text { gado } \\
\text { com } \\
\text { Sulfato } \\
\text { de sódio } \\
\text { anidro }\end{array}$ \\
\hline $\begin{array}{l}\text { Densidade } \\
\text { a } 20^{\circ} \mathrm{C} / \\
(0,850- \\
0,900)\end{array}$ & $\begin{array}{l}0,882 \\
\mathrm{~g} / \mathrm{mL}\end{array}$ & $\begin{array}{l}0,875 \\
\mathrm{~g} / \mathrm{mL}\end{array}$ & $\begin{array}{l}0,872 \\
\mathrm{~g} / \mathrm{mL}\end{array}$ \\
\hline $\begin{array}{l}\text { Acidez / } \\
(0,500 \\
\text { máx })\end{array}$ & $\begin{array}{c}4,2 \mathrm{mg} \\
\mathrm{KOH} / \mathrm{g} \\
\text { óleo }\end{array}$ & $\begin{array}{c}0,5 \mathrm{mg} \\
\mathrm{KOH} / \mathrm{g} \\
\text { óleo }\end{array}$ & $\begin{array}{c}5,2 \mathrm{mg} \\
\mathrm{KOH} / \mathrm{g} \\
\text { óleo }\end{array}$ \\
\hline $\begin{array}{l}\text { Teor de } \\
\text { Glicerol } \\
\text { livre/(0,02) }\end{array}$ & $0,017 \%$ & $0,01 \%$ & $0,002 \%$ \\
\hline $\begin{array}{l}\text { Viscosidad } \\
\text { e a } 40^{\circ} \mathrm{C} / \\
(3,0-6,0)\end{array}$ & $\begin{array}{c}6,83 \\
\mathrm{~mm}^{2} / \mathrm{s}\end{array}$ & $\begin{array}{c}4,77 \\
\mathrm{~mm}^{2} / \mathrm{s}\end{array}$ & $\begin{array}{c}4,71 \\
\mathrm{~mm}^{2} / \mathrm{s}\end{array}$ \\
\hline $\begin{array}{l}\text { Umidade / } \\
(0,500 \\
\max )\end{array}$ & $0,153 \%$ & $0,114 \%$ & $0,747 \%$ \\
\hline
\end{tabular}

Com base nos valores apresentados na Tabela 3, percebe-se que o biodiesel, que foi submetido à rotaevaporação e posteriormente purificado com água alcalina, apresentou resultados condizentes com os valores de índice de acidez dos padrões de análise, para controle de qualidade, exigido pela ANP.

Um parâmetro importante no controle de qualidade do biodiesel é a quantidade de glicerina livre, que tem um limite máximo permitido de $0,02 \%$ pela ANP. Tal resultado significa a adequada separação de fases entre o biodiesel e a glicerina após a reação de transesterificação, facilitada pela centrifugação.

$\mathrm{O}$ valor da viscosidade cinemática, que é um dos parâmetros mais importantes do biodiesel, foi de $6,83 \mathrm{Mm}^{2} / \mathrm{s}$, para o biodiesel lavado com água destilada. Entretanto, tal resultado é relativamente maior do que o limite estabelecido pela $\operatorname{ANP}\left(6,00 \mathrm{~mm}^{2} / \mathrm{s}\right)$.

A densidade do biodiesel, ligeiramente superior a do óleo diesel convencional, exerce efeito direto sobre o desempenho do motor devido ao fornecimento de uma massa ligeiramente maior de combustível em mesma unidade de volume. Este parâmetro está dentro do intervalo de valores estabelecidos pela ANP (DAPIEVE et al., 2014).

A umidade considerada um parâmetro importante, apresentou o valor de $0,747 \%$ para o biodiesel centrifugado com sulfato de sódio anidro. Este valor está acima do que é especificado pela ANP.

As composições e os teores de ésteres etílicos dos biodieseis obtidos a partir da blenda de óleo de fritura com sebo bovino, para os diferentes métodos de purificação utilizados neste trabalho, estão apresentados na Tabela 4. 
Tabela 4 - Composição e teor de ésteres etílicos dos biodieseis.

\begin{tabular}{l|c|c|c}
\hline \multicolumn{1}{c|}{$\begin{array}{l}\text { Ésteres } \\
\text { etílicos }\end{array}$} & $\begin{array}{c}\text { Biodiesel } \\
\text { lavado } \\
\text { com } \\
\text { água } \\
\text { destilada }\end{array}$ & $\begin{array}{c}\text { Biodiesel } \\
\text { centrifuga } \\
\text { do com } \\
\text { água } \\
\text { alcalina }\end{array}$ & $\begin{array}{c}\text { Biodiesel } \\
\text { centrifuga } \\
\text { do com } \\
\text { Sulfato de } \\
\text { sódio } \\
\text { anidro }\end{array}$ \\
\hline $\begin{array}{l}\text { Ácido } \\
\text { Palmítico } \\
\text { (C16:0) }\end{array}$ & $19,3 \%$ & $16,2 \%$ & $18,0 \%$ \\
\hline $\begin{array}{l}\text { Ácido } \\
\text { Esteárico } \\
\text { (C18:0) }\end{array}$ & $8,6 \%$ & $9,3 \%$ & $8,6 \%$ \\
\hline $\begin{array}{l}\text { Ácido } \\
\text { Oleico } \\
\text { (C18:1n9t) }\end{array}$ & $31,7 \%$ & $31,2 \%$ & $30,7 \%$ \\
\hline $\begin{array}{l}\text { Ácido } \\
\text { Linoleico } \\
\text { (C18:2n6) }\end{array}$ & $40,4 \%$ & $43,3 \%$ & $42,7 \%$ \\
\hline Teor (\%) & $57,30 \%$ & $83,17 \%$ & $81,40 \%$ \\
\hline
\end{tabular}

Pela Tabela 4 pode-se constatar que os diferentes métodos de purificação apresentam resultados semelhantes em relação aos ácidos graxos destacando-se os ácidos linoleico (C18:2n6) e oleico (C18:1n9t).

\section{CONCLUSÃO}

A partir dos resultados pode-se verificar que o método de purificação dos ésteres etílicos que apresentou características físicoquímicas dentro das exigências da ANP foi o de evaporação rotativa e centrifugação com adição de água alcalina. Destaca-se neste resultado o de teor de glicerol livre e acidez, $0,5 \mathrm{mg} \mathrm{KOH} / \mathrm{g}$ óleo e $0,01 \%$ respectivamente.

\section{NOMENCLATURA}

ANP: Agência Nacional do Petróleo, Gás Natural e Biocombustíveis.

AOCS: American Oil Chemists' Society AOAC: Association Of Analytical Communities
ASTM: American Society for Testing and Materials

AGL: Ácidos Graxos Livres

\section{REFERÊNCIAS}

ABREU, Paulo Giovanni de. HIGARASHI, Martha Mayumi. CUNHA JUNIOR, Anildo. Transesterificação com catálise ácida de resíduos de gordura de frango para produção de biodiesel: resultados preliminares. Revista EMBRAPA. 2012.

BASHA, S. A.; GOPAL, K. R.; JEBARAJ, R.G. A Review on Biodiesel production, combustion, emissions and performance. Renewable and Sustainable Energy Reviews. v.13. P. 1628-1634.

BERRIOS, M.; SKELTON, R. L. Comparison of purification methods for biodiesel. Chemical Engineering Journal. v. 144, p. 459-465, 2008.

CUNHA, M, E. Caracterização de biodiesel produzido com misturas binárias de sebo bovino, óleo de frango e óleo de soja. f.90. (Mestrado em Química) Universidade Federal do Rio Grande do Sul, 2008.

COLONELli, T. A. S; SILVA, C. Esterificação Heterogênea dos Ácidos Graxos Livres do Óleo da Polpa de Macaúba (Acrocomia aculeata) em Etanol. Semina: Ciências Exatas e Tecnológicas. v. 35. n. 1. p. 25-38, 2014.

DAPIEVE, D. R. BITTENCOURT, P. R. S. LUKASIEVICZ, G. V. B. DEIMLING, C. V. Influência da temperatura nas propriedades físicas em misturas de diesel/biodiesel. II Simpósio de Bioenergia e Biocombustíveis do Mercosul. Foz do Iguaçu, 2014. 
DIB, F. H. Produção de biodiesel a partir de óleo residual reciclado e realização de testes comparativos com outros tipos de biodiesel e proporções de mistura em um moto-gerador. Dissertação (Mestrado em Engenharia Mecânica) - Universidade Estadual Paulista. Faculdade de Engenharia de Ilha Solteira, Ilha Solteira, São Paulo, 2010 .

GEORGOGIANNI, K. G.; KATSOULIDIS, A.P., POMONIS, P.J., KONTOMINAS, M. G. Transesterification of soybean frying oil to biodiesel using heterogeneous catalysts. Fuel Processing Technology, v. 90, p.671-676, 2009.

HOLANDA, A. CÂMARA, G.M.S. Potencial da cultura da soja como fonte de matéria-prima para o Programa Nacional de Produção e Uso do Biodiesel. In: CÂMARA, G. M. S. \& HEIFFIG, L. S. (coord.):Agronegócio de Plantas Oleaginosas: Matérias-Primas para Biodiesel. Piracicaba: ESALQ. p.123 - 153.2004.

INSTITUTO ADOLFO LUTZ, Normas Analíticas. Métodos Químicos e Físicos para Análise de Alimentos, v.1, $3^{\mathrm{a}}$ ed., São Paulo, 1985.

KNOTHE, G. Dependence of biodiesel fuel properties on the structure of fatty acid alkyl esters. Fuel Processing Technology, v. 86, p. 1059-1070, 2005.

KNOTHE, G.; VAN GERPEN, J.; KRAHL, J.; RAMOS, L. P., Manual de biodiesel, Ed. Edgard Blucher, Sao Paulo, 2006, 340p.

LEE, H.V.; YUNUS, R.; JUAN, J.C.; TAUFIQ-YAP, Y.H. Process optimization design for jatropha-based biodiesel production using response surface methodology. Fuel Processing Technology, v. 92, p. 2420-2428, 2011.
LEUNG, D.Y.C., GUO,Y. Transesterification of neat and used frying oil: Optimization for biodiesel production. Fuel Processing Technology. v. 87, p. 883-890, 2006.

MAGALHÃES, F. C. Blenda sebo/soja para produção de biodiesel: Proposta de um processo batelada homogêneo como alternativa para agricultura familiar. 2010, Dissertação (Mestrado em Química Tecnologia e Ambiental) -Programa de Pósgraduação em Química Tecnologia e Ambiental, Universidade Federal do Rio Grande, Rio Grande, 77p.

MEDEIROS, J.F; SOUZA, G.K; PEREIRA, N.C; GOMES, M.C.S; LIMA, O.C.M. Análise da Produção de Biodiesel de Óleo de Soja e Purificação por Centrifugação. Biochemistry and Biotechnology Reports. . v. 2 , n. 3 p. $142-145,2013$.

OLIVEIRA, S.M; DALCOLLE, J.C; PEREIRA, N.C. Tratamento e caracterização físico-química do óleo de fritura e sebo bovino para desenvolvimento de blendas líquidas capazes de serem destinadas para produção de biodiesel etílico. Fórum Ambiental da Alta Paulista. v. 9, n. 1, p. 112-122, 2013.

PARENTE, E. J. S. Biodiesel: uma aventura tecnológica num país engraçado. Fortaleza: Unigráfica, 66p. 2003.

ROSENHAIM, R. Avaliação das propriedades fluído-dinâmicas e estudo cinético por calorimetria exploratória diferencial pressurizada (PDSC) de biodiesel etílico derivado de óleo de fritura usado. f.130. (Tese Doutorado). Universidade Federal da Paraíba, 2009.

UZUN, B.B., KILIC, M., OZBAY, N., PUTUN, A.E., PUTUN, E. Biodiesel 
production from waste frying oils: Optimization of reaction parameters and determination of fuel properties. Energy. v. 44, p. 347-351, 2012.

ZHANG, Y; DUBÉ, M. A; MCLEAN, D. D; KATES, M. Biodiesel production from waste cooking oil: 1. Process design and technological assessment. Bioresource Technology. v. 89, p. 1-16, 2003.

ZHENG, S; KATES, M; DUBÉ, M. A; MCLEAN, D. D. Acid-catalyzed production of biodiesel from waste frying oil. Biomass and Bioenergy. v. 30, p. 267-272, 2006.

ZUNIGA, A. D. G; PAULA, M. M; MARTINS, E. C. A; SILVA, D. X; TELISROMERO, J. Revisão: Propriedades físicoquímicas do biodiesel. Pesticidas: r. ecotoxicol. e meio ambiente, Curitiba, v. 21, p. 55-72, 2011.

\section{AGRADECIMENTOS}

Agradecimento à CAPES pelo o apoio financeiro. 